\author{
Erkie Asmare ${ }^{\star}$, Dereje Tewabe, Birhan \\ Mohamed and Beniyam Hailu \\ Amhara Region Agricultural Research Institute, \\ Bahir-Dar Fisheries and Other Aquatic Life Research \\ Center P.O.Box 794, Bahir-Dar, Ethiopia \\ Dates: Received: 26 October, 2015; Accepted: 20 \\ November, 2015; Published: 23 November, 2015 \\ *Corresponding author: Erkie Asmare Beyene, \\ Amhara Region Agricultural Research Institute, \\ Bahir-Dar Fisheries and Other Aquatic Life Research \\ Center, Bahir-Dar, Ethiopia, Tel: +251 918271253; \\ E-mail: erkie.asmare@yahoo.com \\ www.peertechz.com \\ ISSN: 2455-8400
}

Keywords: Solar tent; Hygiene; Organoleptic; Price for dried fish

\section{Research Article \\ Pre-Scaling Up of Solar Tent Fish Drier in Northern and North Western Part of Lake Tana, Ethiopia}

\section{Introduction}

Fish provide the main source of animal protein to about one billion people globally. Fisheries are an important part of food security, particularly for many poor people in developing countries. In low income food deficient countries, they make up $22 \%$ of animal protein consumption overall [1]. Fish may also be the sole accessible and/or affordable source of animal protein for poor households in urban or peri-urban areas. Fish is, however, highly susceptible to deterioration without any preservative or processing measures [2].

Fish is an important food item that has significant socioeconomic contribution as a source of income, employment and cheap protein for marginal people in developing countries including Ethiopia. Lake Tana is one of the major fisheries in Ethiopia [3]. Small fish are especially important for poor consumers, as they can be purchased in small quantities at low cost. Even though the estimated production from Ethiopia commercial fishery is about 51,481tones per year, the actual catch were 15,389tones per year in 2001. FAO estimates fish post harvest losses is among the highest for all commodities; where Ethiopia losses one third of the annual production, which is about 5130tones per year $[4,6]$.

In Lake Tana fisheries there are ten districts that have a potential for fishing, among these districts Gondar zuriya, Dembiya and Alefa districts have taken the main share. The amount of fish caught is high in these areas but due to market distance and discouraging price for dried fish the fishers couldn't obtain the expected benefit. The post harvest losses in the study area are the main challenge due to nonexistence of appropriate preservative methods and expensiveness of other drying technologies. In Gondar zuriya, Dembiya and Alefa woredas/districts the main fish preservative methods are sun drying and salting.

Sun drying and salting still has many limitations, such as long period of drying during cloudy climate. In areas of high humidity, it is often difficult to dry the fish to low moisture content [5]. Sun drying of fish often results in low quality as a result of slow drying, insect infestation and contamination from air borne dust etc [3,5]. For getting better quality-dried fish, it is very essential to use improved methods of fish drying. Moreover, it is also important to maintain required hygiene during the different phases of fish drying by using solar tent fish drier [5,6]. In view of this, the present study aimed to: (1) minimize post harvest losses by improving the shelf life dried fish; (2) enhance technology multiplication and dissemination system; (3) create clear insight about the technology implementation.

\section{Materials and Methods}

\section{Site selection and providing training}

This study was carried out in the northern and northwest part of Lake Tana. The study areas were selected based on the existence of surplus fish production and fish drying experience. Based on the 
budget and time we execute the activities in a cluster approach. The sites were selected based on their representativeness of other districts.

The study areas were selected in purposive sampling methods: at the first stage Dembya, Alefa, and Gondar zuriya woredas were selected purposively. At the second stage two kebeles at each woredas (Mangie and Gurandie from Dembya woreda; Esey-Debir and Dengel-ber from Alefa wored; Enfranze and Firkha-Dangurie from Gondar zuriya woreda) were selected and finally fishers that have drying experience were selected for scaling up the technology.

The activity was conducted in participatory approach. Fishers' teams were established (6 groups) on village based clustering and 6 drying tents were provided to the groups. Practical and theoretical trainings were provided to all groups to make them aware of for preparing the tent from readily available materials. To facilitate the pre scale up activities, focal persons were assigned from each of the groups.

\section{Fishing and drying}

Samples of the fish species labeobarbus intermedius were filleted using knife, weighed, and soaked in salt solution 60 gram salt dissolved in one liter of water as recommended by Assefa T. et al. (2008). Weight after drying has been taken to obtain the calculated weight losses.

\section{Method of data collection}

Data were collected using data sheet for socioeconomic and social data. Socio-economic researchers collect social data using PRA tools such as focus group discussion and individual interview. Structured and open ended questionnaires were prepared and filled. Information collected were: availability of inputs, ease of management and operation of the tents; group interaction and skill exchange during utilization of the tents, labor utilization, marketability of the product, benefit gained; personal opinions and observation on their feelings, observations, suggestions, and other's views on the tents; perception and attitude towards the technology.

\section{Methods of data analysis}

Descriptive statistics such as percentage, mean, standard deviations were also used. Social analysis such as perception and attitude of farmers and stakeholders towards the technologies were analyzed by using likert scale scoring. To know stakeholders' level of agreement on different aspects of the technology score were given: strongly agree $=5$; agree $=4$; indifferent $=3$; disagree $=2$; strongly disagree $=1$. Sum score were calculated by using a formula $=$ frq. strongly agree ${ }^{\star} 5+$ frq. agree ${ }^{\star} 4+$ frq. indifferent ${ }^{\star} 3+$ frq. disagree ${ }^{\star} 2$ + frq. strongly disagree ${ }^{\star} 1$; where frq is frequency. Finally the average score were derived by dividing sum score to total sample size.

\section{Responsibilities sharing and exit strategy}

The main stakeholders in the activity and training were: local fishers, woreda and kebele fish experts, woreda agriculture experts and development agent, kebele administrators, environmental protection experts, trade and transport (market linkage and promotion) expert, and small enterprise developments (business development service) expert.
To secure the technologies sustainability responsibilities were shared among stakeholder. In addition all trained fisher groups are promised to prepare solar tent fish dryer at their home by teaching and helping untrained neighbours. There were sharing of tasks among stakeholders to further disseminate technology in the future by continuous follow up, support and consultation.

\section{Results and Discussions}

\section{Demographic characteristics of sample households}

This study was based on the information collected from a total of 38 sample households and all of these are participate in fishery sector in a full time, seasonal and part time basis. The age structure of the sample households shows an average of 33.97 years. This implies that most of the respondents have had adequate experience on fishing activity. Sample households average family size is 4.6 and the average distance from the home to the main road is 63.89 minutes of walk. This shows fisher travels for an average of one hour to sale their catch to the nearest market.

Inaccessibility of road to sale catches exacerbates the spoilage rate and increase post-harvest loses. Post harvest processing is operated by both men and women; during the study $55.3 \%$ of the respondents were men.

The education status of the respondents involved in fishing activities can be described as illiterate except the $47.7 \%$ of literate respondents. This indicates that the fishing activity is open not only for poor and illiterate communities but also for educated peoples.

The main means of livelihood in the study area is agriculture (cropping) activity. Of the total households, $36.8 \%$ of them participate mainly in fishing activities. This infers that fishing is the best means of income generating mechanism besides cropping and livestock rearing (Table 3 ).

Most of the respondents participate seasonally and full time which accounts $36.8 \%$ of each. Farmers in the study area participate in fishing seasonally, besides livestock rearing and crop productions. During peak seasons (June to November) farmers mainly focus on agricultural activities like crop production and livestock. However, it doesn't mean that seasonal participants don't go to fishing during pick seasons; because during holyday and religious day (ploughing is not allowed) they go to fishing for their consumption. On the other hand, farmers who have a certain amount of farm land are part time participants as supplementary for income generation.

\section{Training and characteristics of dried fish}

The training was held in Dembiya and Gondar Zuriya woreda with a total of 107 participants. With these participants $35.5 \%$ of them were female participants. The study areas are known in their production potential but market problems and non-existence of appropriate fish preservative methods exacerbate fish post harvest loses. The training was composed of practical and theoretical components to enhance the stakeholder's knowledge about the technology Figure 1.

The trainings were mainly focused on: advantages of using solar tent fish drier and way of construction in practical; fish preservative 
Table 1: Age, family size, average catch and percentage of sale of the sample household.

\begin{tabular}{|c|c|c|c|c|c|}
\hline & $\mathbf{N}$ & Minimum & Maximum & Mean & Std. Deviation \\
\hline Age & 38 & 22 & 55 & 33.97 & 9.243 \\
\hline Family size & 36 & 1 & 8 & 4.64 & 1.743 \\
\hline *Distance to main road & 38 & 0 & 180 & 63.89 & 52.562 \\
\hline Average catch in kg. & 35 & 2 & 30 & 8.20 & 7.095 \\
\hline$\%$ sale from the catch & 36 & 75 & 100 & 93.47 & 8.768 \\
\hline
\end{tabular}

Table 2: Education level and sex of the respondents.

\begin{tabular}{|l|c|c|c|c|}
\hline \multicolumn{1}{|c|}{ Education } & Freq. & Percent & Sex & Frequency \\
\hline illiterate & 21 & 55.3 & Male & 21 \\
\hline literate & 17 & 44.7 & Female & 17 \\
\hline Total & 38 & 100.0 & Total & 34.3 \\
\hline
\end{tabular}

Table 3: Means of livelihood and type of participation in the fishery sector.

\begin{tabular}{|l|c|c|l|r|}
\hline & Frequency & Percent & \multicolumn{2}{|c|}{ Engagement } \\
\hline Fishery only & 14 & 36.8 & Full time & \multicolumn{1}{|c|}{ Prequency } \\
\hline Agriculture with fishing & 24 & 63.2 & Part time & 14 \\
\hline & & & Seasonal & 10 \\
\hline Total & 38 & 100.0 & Total & 36.3 \\
\hline
\end{tabular}

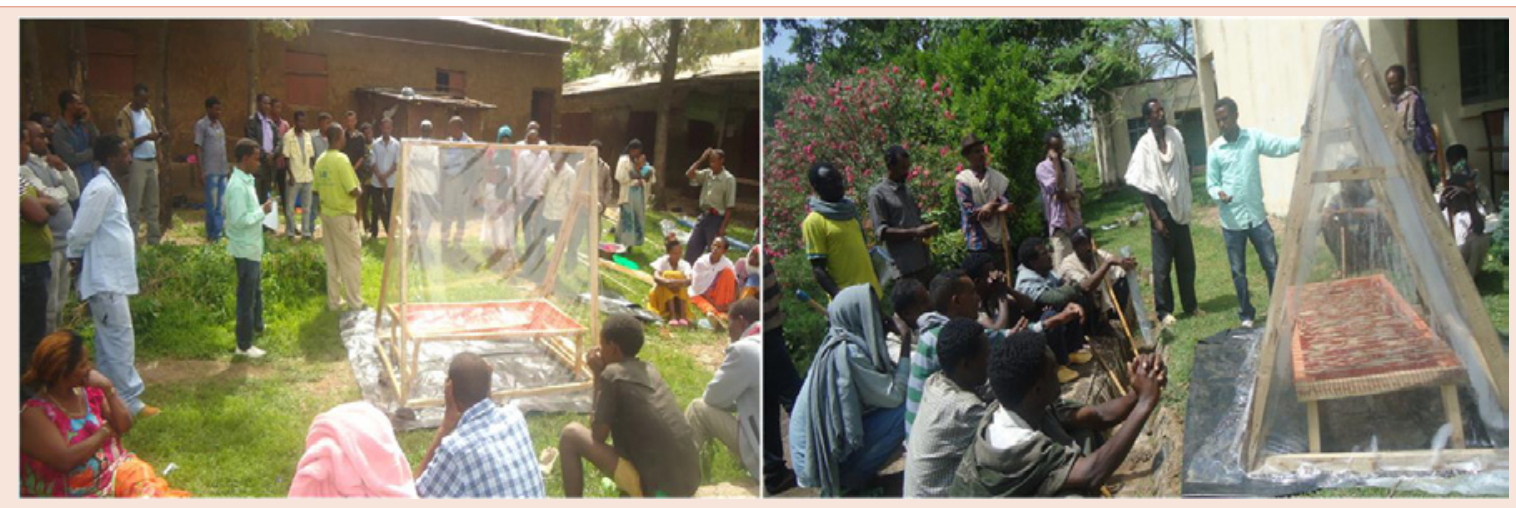

Figure 1: Solar tent fish drier at Gondar zuriya and Dembiya woredas.

type and technique; pre and post harvest handling methods; methods of changing fish left over to animal and human consumption. The main participants in the training were: local fishers, district and kebele fish experts, district agriculture experts and development agents, kebele administrators, environmental protection experts, trade and transport (market linkage and promotion) experts, and small enterprise developments (business development service) expert.

The solar tent fish drier was prepared from readily available materials such as; wood, white and black plastic, nail, rope and mesh wire. For the scaling up six tents were prepared with a size of 2meter height and 1.7 meter length to dry Labeobarbus intermedius fish species. The driers provide hygienic conditions for fish drying and they could be constructed from reasonably priced and readily available materials.

To know the total weight losses, initial weight before drying and final weight after dried have registered. The initial weight of gutted fish before dried was 2kilogram in each tent and the salt amount used was 60 gram per liter of water in brine form. After the gutted fish have been immersed in the salt solution for five minutes, drying has started by stowing on the prepared rack. In the first day, the weight losses have increased at an increasing rate. At the second day the weight loss of dried fish continues to increase but it was at decreasing rate. The weight of dried fish becomes stable and dried well in the third day and the final weight data were registered at this time. 
Table 4: Benefit gained as a result of using the technology.

\begin{tabular}{|c|c|c|}
\hline & Frequency & Percent \\
\hline Reduce post harvest loss & 5 & 13.5 \\
\hline Organoleptic (taste, ouder and appearance) of the fish is better & 7 & 18.9 \\
\hline Shelf life of the fish becomes prolonged & 11 & 29.7 \\
\hline It is hygienic & 5 & 13.5 \\
\hline Dry fishes faster with increased shelf-life & 6 & 16.2 \\
\hline Reduce post harvest loss and become hygienic & 3 & 8.1 \\
\hline Total & 37 & 100.0 \\
\hline
\end{tabular}

Table 5: household's level of agreement on the availability of inputs.

\begin{tabular}{|l|c|c|c|c|}
\hline Perceptions & Strongly agree & Agree & Indifferent & Disagree \\
\hline Available constructing inputs & $21.1 \%$ & $34.2 \%$ & $28.9 \%$ & $15.8 \%$ \\
\hline Not labour intensive & $50.0 \%$ & $31.6 \%$ & $13.2 \%$ & $5.3 \%$ \\
\hline Not costly to construct & $10.8 \%$ & $27.0 \%$ & $48.6 \%$ & $13.5 \%$ \\
\hline Easy to implement & $42.1 \%$ & $39.5 \%$ & $13.2 \%$ & $5.3 \%$ \\
\hline Easy to manage & $39.5 \%$ & $50.0 \%$ & $10.5 \%$ & $0.0 \%$ \\
\hline Fish holding capacity is good & $5.3 \%$ & $31.6 \%$ & $55.3 \%$ & $5.0 \%$ \\
\hline
\end{tabular}

Table 6: Household's level of agreement on the fish dried by STFD.

\begin{tabular}{|l|c|c|c|c|}
\hline Perceptions & Strongly agree & Agree & Indifferent & Disagree \\
\hline Hygienically high & $86.8 \%$ & $13.2 \%$ & $0.0 \%$ & $0.0 \%$ \\
\hline Fishes dried quickly & $52.6 \%$ & $42.1 \%$ & $5.3 \%$ & $0.0 \%$ \\
\hline Good taste, texture, odder and color & $73.7 \%$ & $26.3 \%$ & $0.0 \%$ & $0.0 \%$ \\
\hline Shelf life of the dried fish is longer & $89.5 \%$ & $10.5 \%$ & $0.0 \%$ & $0.0 \%$ \\
\hline Post harvest lose reduced & $65.8 \%$ & $34.2 \%$ & $0.0 \%$ & $0.0 \%$ \\
\hline Marketability is good & $26.3 \%$ & $13.2 \%$ & $50.0 \%$ & $5.3 \%$ \\
\hline High price for fish dried by solar tent & $13.2 \%$ & $23.7 \%$ & $13.2 \%$ & $28.9 \%$ \\
\hline I will adopt the technology for future & $78.9 \%$ & $21.1 \%$ & $0.0 \%$ & $21.1 \%$ \\
\hline
\end{tabular}

Table 7: Likert score on the perception about inputs and management.

\begin{tabular}{|l|c|}
\hline Perceptions & Sum score \\
\hline Available inputs to prepare solar tent fish drier & 137 \\
\hline Not labour intensive & 162 \\
\hline Not costly to construct & 124 \\
\hline Easy to implement & 3.6 \\
\hline Easy to manage & 159 \\
\hline Fish holding capacity of the solar tent is good & 163 \\
\hline
\end{tabular}

Studies in agreement with our findings investigates solar tent drier required less time to dry which is about 58 hours [7]. Reason behind this was circulation of hot air within solar tent drier, which increased internal drier temperature and reduced drying time. Fish dried by solar tent require 3 days to reach to the lowest moisture content level [5]. Based on our study, the final weight of dried fish was 0.8 kilogram. When the final weight of dried fish compared with the initial weight there is 0.6 kilogram weight loss per kilogram when fish dried in the tent. Weight loss $=\left(\left(\mathrm{W}_{\mathrm{i}}-\mathrm{W}_{\mathrm{f}}\right) / \mathrm{W}_{\mathrm{I}}\right)^{*} 100=(1 \mathrm{k} \cdot \mathrm{g}-$ $0.4 \mathrm{k.g}) / 1 \mathrm{k.g})^{\star} 100=60 \%$.

\section{Benefits gained from solar tent fish drier}

In the study area fisher's start drying when production becomes high because of the currently emerging dried fish market to Sudan encourages fisher to practice fish drying. However, sun drying still has numerous limitations; such as drying process is not quick during 
Table 8: Likert score on the perception about fish dried by solar tent fish drier

\begin{tabular}{|l|c|c|}
\hline Perceptions & $\begin{array}{c}\text { Sum } \\
\text { score }\end{array}$ & $\begin{array}{c}\text { Average } \\
\text { score* }\end{array}$ \\
\hline Hygienically high & 185 & 4.9 \\
\hline Fishes dried quickly & 170 & 4.5 \\
\hline The taste, texture, odder and color is good & 180 & 4.7 \\
\hline Shelf life of the dried fish is longer & 186 & 4.9 \\
\hline Post harvest lose reduced & 177 & 4.7 \\
\hline More marketable than the traditional & 133 & 3.5 \\
\hline High price for fish dried by solar tent than the local & 106 & 2.8 \\
\hline I will adopt the technology for future & 182 & 4.8 \\
\hline
\end{tabular}

Table 9: Challenges for preparing and using solar tent fish drier.

\begin{tabular}{|l|c|c|}
\hline & Frequency & Percent \\
\hline inaccessibility of road & 2 & 5.3 \\
\hline input scarcity & 10 & 26.3 \\
\hline knowledge gap & 1 & 2.6 \\
\hline weak extension linkage & 2 & 5.3 \\
\hline knowledge gap and shortage of input & 4 & 10.5 \\
\hline market problem for dried fish and input scarcity & 6 & 15.8 \\
\hline $\begin{array}{l}\text { market problem for dried fish, input scarcity and weak } \\
\text { extension linkage }\end{array}$ & 8 & 21.1 \\
\hline white polythene is not accessible at local market & 5 & 13.2 \\
\hline Total & 38 & 100.0 \\
\hline
\end{tabular}

cloudy climate, contamination and have no good quality. These could have significant impact on the shelf life of the fish hence; drying by using STFD reduces susceptibility of fishes for spoilage by protecting fishes from dust, rain and insect contamination.

STFD enables the fish to dry quickly and uniformly since the temperature in the tent is above room temperature. A uniformly and quickly dried fish is attractive to see and suitable to eat. Therefore, solar tent fish dryer increases the shelf-life, maintains the quality of the fish in terms of its nutrient, flavor, texture, and appearance, provides ease of handling, and reduces post catch losses thereby ensuring continuous availability of cheap animal protein to the people all year round.

\section{Perception of the fishers and stakeholders}

The perception and attitude data collected were mainly focus on input availability, cost of construction, and quality of the product, marketability and future fate of the technology. The respondents and stakeholder's attitude towards the technology were good in most aspects.

The respondents were asked their level of agreement or disagreement on the availability of construct materials, $34.2 \%$ of them agree and $15.8 \%$ were disagreed on the availability of constructing materials specially the durable white and black polyethylene is difficult to get and purchase.

Even though STFD can be constructed from locally available materials, it requires some materials to be purchased such as; nail, white and black polyethylene and mesh wire. Regarding the cost of construction, $27 \%$ of the respondents agree as it is costly but $48.6 \%$ are neither agree nor disagree which means there is a frustration about cost for purchasing inputs. The ease of management (maintaining and operating) and implementing construction is easy. But one issue raised by the respondents was fish holding capacity of the tent is not different from the traditional methods of drying.

The tent speeds up the drying process by raising the temperature above room temperature especially when the weather is not ideal. In addition STFD is water proof; the fish doesn't therefore need to be moved when it rains. The hygiene of dried fish with in the tent is remarkable since fishes inside the tent are protected from dust, dirt, and insect attack. The hygiene, rate of drying and organoleptic situation were good. Out of the total respondents $86.8 \%$ of them strongly agrees that fish dried by STFD are hygienically good compared the traditional method of drying.

Stakeholders and fishers strongly agree that, rate of dry, organoleptic taste, and shelf life after dried was good. Based on this we can conclude that, good hygiene and earliness of drying reduces spoilage rate of caught. This results in increased shelf life of the fish which have a significant contribution to reduce post harvest losses.

Based on the likert score respondents agree that, STFD is easy to implement and manage. The hygiene, taste, texture, odder, color and prolonged shelf life make the technology smart. Furthermore; STFD reduces post harvest lose by drying quickly during surplus of production with no additional labour cost. These attribute of the technology aspires the fishers to further adoption in the future.

On the other hand; available inputs, cost of constructing, fish holding capacity of the tent, and marketability of fish dried by STFD hesitates fisher for extensive adoption. Fisher strongly asserts absence of differed price for fish dried by solar tent may hinder adoption level in the future if market problem couldn't get solution.

\section{Major challenges for using the technology}

Using STFD has certain problems as raised by sample households. Among challenges: input scarcity such as; white and black polythene; market problem especially price for fish dried by the technology is not encouraging; weak extension linkage the fishery sector; knowledge gap for using the technology, and inaccessibility of road. The main challenges in using STFD are the market and price for fish dried by STFD is not different from the traditional. This couldn't motivate the fishers to use and invest on STFD.

\section{Conclusions and Recommends}

Local way of drying (sun drying) has many limitations, such as long period of drying during cloudy climate. In areas of high humidity, it is often difficult to dry the fish to low moisture content. Fish dried by sun often results in low quality as a result of slow drying, insect infestation and contamination from air borne dust etc. However, drying fish by solar tent fish dryer enables to produce hygienic, high quality, organoleptically good dried fish with low cost. By drying quickly it is possible to reduce post harvest losses thereby ensuring continuous availability of cheap animal protein. 
Market price for fish dried by STD is not different from the traditional. This could future threat for fishers to use and invest on STFD. If the technology is expected to play its role, the following issue requires due attention: promotion and market linkage for the quality dried fish; support fishers by delivering scarce inputs such as; white and black polythene; strengthen extension linkage in the fishery sector; drying a spoiled fish must be banned; fill knowledge gaps about the technology by continuous follow up and support is very important; further scaling out of the technology.

\section{Acknowledgment}

The authors gratefully acknowledge the contribution of fishers, researchers, technical assistants, car drivers and extension workers who made tremendous efforts to make the research successful. The financial support of Amhara Regional Agricultural Research Institute (ARARI) to conduct this research is also very much appreciated.

\section{References}

1. Demeke Teklu (2013) Fish post-harvest technologies as a mean of food and nutrition security. International Journal of Fishery Science and Aquaculture Vol. 1: 024-027.

2. Akangbe JA, BankoleY, Ajibola B (2013) Adoption of smoking chokor for fish processing in kwara state. Department of Agricultural Extension and Rural Sociology, University of Ilorin, Nigeria. Russian Journal of Agricultural and Socio-Economic Sciences 3: 026-030

3. Assefa Tessem, Sewmohon Demssie, Goraw Goshu, Behailu Bekele, Admasu Fantahun and Belay Bezabeih, et al. (2008) Evaluation of solar tent and drying rack methods for the production of quality dried fish in Lake Tana area: In proceedings of the 3rd Annual Regional Conference on Completed Livestock Research Activities, 1-4 September, Bahir-Dar. Edited by Solomon Gizawu, Fisseha Moges and Halima Hassen, 15-26.

4. FAO (2003) Fishery country profile -the federal democratic republic of Ethiopia, Addis Ababa: FAO.

5. Trim DS and CA Curran (1983) A comparative study of solar and sun drying of fish Ecuador. Rep.Trop.Prod.Inst.London, pp: 38.

6. FAO (1992). Fish utilization and marketing. Technical paper 329.Italy. Rome.

7. Relekar SS, Joshi SA, Gore SB, Kulkarni AK (2014) Effect of improved drying methods on biochemical and microbiological quality of dried small head ribbon fish, Lepturacanthus savala. Department of Fish Processing Technology \& Microbiology, College of Fishery Science, Telangkhedi, Nagpur. International Journal of Fisheries and Aquatic Studies 1: 60-66

8. Nerquaye-Tetteh G, Eyeson KK and Tette-Marmon (1978) Studies on "Bomone" - A Ghanaian fermented fish product. Accra, Ghana, Food Research Institute (CSIR) 